\title{
Clinical utility of landiolol for use in coronary $\mathrm{CT}$ angiography
}

This article was published in the following Dove Press journal:

Research Reports in Clinical Cardiology

23 November 2015

Number of times this article has been viewed

\author{
Nobuo Tomizawa' \\ Yayoi Hayakawa' \\ Shinichi Inoh' \\ Takeshi Nojo' \\ Sunao Nakamura ${ }^{2}$ \\ 'Department of Radiology, \\ ${ }^{2}$ Department of Cardiology, New \\ Tokyo Hospital, Matsudo, Chiba, Japan
}

\begin{abstract}
Although remarkable advancement in computed tomography (CT) has been achieved, heart rate control is important to maintain an optimal image quality in coronary CT angiography. Oral or intravenous $\beta$-blockers are used as premedication for this purpose. Landiolol was developed as a $\beta$-blocker with very high cardioselectivity $(\beta 1 / \beta 2=255)$ and short half-life (4 minutes). In this review, we report the pharmacological features and usage of landiolol and also its effects on heart rate and image quality in coronary CT angiography. In addition, we discuss the safety of landiolol.
\end{abstract}

Keywords: coronary computed tomography angiography, heart rate, image quality

\section{Introduction}

The application of coronary computed tomography (CT) angiography as a tool for the diagnosis of coronary artery disease (CAD) has become widespread owing to its high diagnostic performance. ${ }^{1}$ Although remarkable advancement in CT has been achieved, heart rate control is highly important to maintain an optimal image quality. ${ }^{2} \mathrm{~A}$ stable heart rate lower than 65 beats per minute $(\mathrm{bpm})$ is recommended when a typical CT scanner is used during coronary CT angiography. ${ }^{3,4}$ Oral or intravenous $\beta$-blockers are used in order to achieve an optimal heart rate during the scan. ${ }^{5}$ Oral metoprolol or propranolol is typically given as a premedication as it is most effective at 1 hour after administration. ${ }^{6}$ Intravenous $\beta$-blockers are used when heart rate control on site is not enough. Hence, urgent heart rate reduction is necessary. However, the long half-life of intravenous metoprolol or propranolol (approximately 2-3 hours) is a shortcoming of these agents $^{7-11}$ because patients need to be observed for some time after coronary CT examination is performed. In addition, metoprolol has a low $\beta 1$-selectivity and propranolol displays no significant $\beta$-adrenergic selectivity. ${ }^{12}$ This raises a concern regarding adverse effects such as peripheral vasoconstriction or bronchospasm induced by the $\beta 2$-blocking effect. ${ }^{5,7}$ Thus, a $\beta$-blocker with a short half-life and high cardioselectivity is ideal to use as an intravenous $\beta$-blocker for coronary CT angiography.

Esmolol is the first ultrashort-acting $\beta$-blocker with a fairly good cardioselectivity. ${ }^{10,13}$ Landiolol was developed in Japan and approved for clinical use in 2002, 9,14,15 which further increased its cardioselectivity and shortened its half-life by replacing the side chain. The cardioselectivity of landiolol is much higher than that of esmolol ( $\beta 1 / \beta 2=255$ vs 33) and its half-life is shorter (4 minutes vs 9 minutes). ${ }^{9,10,13,16,17}$ Landiolol (Corebeta; Ono Pharmaceutical, Osaka, Japan) has been approved as a premedication for coronary CT angiography in Japan since $2011 .{ }^{18}$ Landiolol would be an ideal intravenous $\beta$-blocker to achieve an optimal image quality in coronary CT angiography.
Correspondence: Nobuo Tomizawa Department of Radiology, New Tokyo Hospital, I27I Wanagaya, Matsudo, Chiba, Japan, 270-2232

$\mathrm{Tel}+814771 \mathrm{I} 8700$

Fax +8I 473928718

Email tomizawa-tky@umin.ac.jp
Research Reports in Clinical Cardiology 2015:6 145-152

Dovepress

http://dx.doi.org/10.21 477/RRCC.S77559

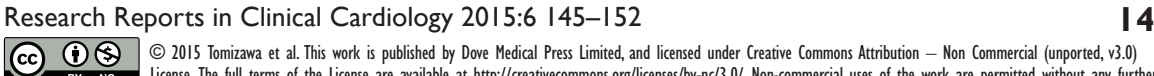
permision from Dove Medical Press limitede, provided the work is properly attributited. Permisisions beyond the scope of the license are administered by Dove Medical Press Limited. Information on how to request permisision may be found at hthp:///www.dovepress 
In this review, we report the pharmacological features and usage of landiolol, as well as its effects on heart rate and the image quality in coronary CT angiography. In addition, we will discuss the safety of landiolol.

\section{Pharmacological features of landiolol}

Esmolol is the first ultrashort-acting $\beta$-blocker with a fairly good cardioselectivity of $\beta 1 / \beta 2=33 \cdot{ }^{10,13}$ The ultrashort duration of esmolol is due to the rapid hydrolysis of its alkyl ester link. ${ }^{13}$ Landiolol was developed to have better activity and selectivity compared with esmolol. ${ }^{10,19}$ Replacing the isopropyl group with the 2,2-dimethylethylurea function increased the $\beta$-blocking activity when compared with that of esmolol. Higher cardioselectivity was achieved by replacing the urea function with morpholinocarbonylamino moiety and the $S$-isomer further increased the cardioselectivity compared with the $R$-isomer (Figure 1). ${ }^{13}$

Landiolol has similar pharmacological characteristics to those of esmolol, but its $\beta 1$-selectivity is higher $(\beta 1 / \beta 2=255 \text { vs 33) })^{9,10,13,16,17}$ and half-life shorter ( 4 minutes vs 9 minutes) than those of esmolol. ${ }^{16}$ The $\beta$-blocking activity of landiolol was also greater by six to eight times that of esmolol in an in vivo canine model study. ${ }^{20}$ Because of the short half-life, the heart rate returned to its baseline value within 5 minutes after landiolol injection in rabbits. ${ }^{10}$ Landiolol is also less cardiodepressive; hence, hypotension is less frequent when landiolol is used than when esmolol is used. ${ }^{10,21-23}$

\section{Clinical use of landiolol}

Landiolol was initially used in various clinical situations. Continuous infusion of landiolol at a dose of $0.5-80 \mu \mathrm{g} / \mathrm{kg} / \mathrm{min}$ is effective for patients with tachyarrhythmia such as paroxysmal atrial fibrillation, paroxysmal supraventricular tachycardia,



Figure I Molecular structure of landiolol hydrochloride. and ventricular tachycardia. ${ }^{24}$ Landiolol is also effective for patients with tachycardia in pheochromocytoma. ${ }^{25,26}$

Landiolol is used to treat tachycardia during operation. Tachycardia in response to endotracheal intubation could be attenuated by $0.1-0.3 \mathrm{mg} / \mathrm{kg}$ landiolol injection, without affecting the blood pressure during the induction of anesthesia. ${ }^{27}$ One study showed that up to $0.3 \mathrm{mg} / \mathrm{kg}$ landiolol reduced the heart rate during anesthesia by $15 \mathrm{bpm} .^{28}$ Continuous injection of landiolol at $0.04 \mathrm{mg} / \mathrm{kg} / \mathrm{min}$ could also prevent tachycardia during tracheal extubation. ${ }^{29}$

In patients who undergo cardiac surgery, $\beta$-blockers are administered perioperatively without contraindications to reduce the incidence of postoperative atrial fibrillation. ${ }^{9,30}$ Landiolol has been shown to inhibit postoperative atrial fibrillation after coronary artery bypass surgery, ${ }^{9,14,15,31-33}$ acute type A aortic dissection repair, ${ }^{34}$ and heart valve surgery. ${ }^{9,35}$ One study showed that landiolol was more effective than diltiazem for patients with postoperative atrial fibrillation after open heart surgery. ${ }^{36}$ Landiolol is also used after percutaneous coronary intervention. Early intravenous administration of landiolol in patients with acute myocardial infarction undergoing percutaneous coronary intervention could have the potential to improve cardiac function in the chronic phase. ${ }^{37}$

An intravenous $\beta$-blocker, including landiolol, is effective during electroconvulsive therapy for patients with severe depression. ${ }^{38}$ This is because the released catecholamine may last several minutes, which causes tachycardia resulting in coronary ischemia in patients at risk. ${ }^{39}$ With landiolol of more than $0.125 \mathrm{mg} / \mathrm{kg}$, significant effects were found in reducing the increase in heart rate during electroconvulsive therapy. ${ }^{40-44}$

\section{Effects of heart rate on image quality and radiation exposure of coronary CT angiography}

The image quality and the diagnostic ability of coronary CT angiography dramatically improved with the development of the CT machine. Initial coronary CT angiography was performed using four-row CT. Giesler et $\mathrm{al}^{45}$ reported in 2002 that the overall sensitivity decreased from $62 \%$ to $33 \%$ when the heart rate was over $70 \mathrm{bpm}$. The slow gantry rotation time of $500 \mathrm{~ms}$ would limit the temporal resolution to $125-250 \mathrm{~ms}$, thus the image quality was suboptimal for diagnosis. Sixteen-row CT became available several years later, and Heuschmid et $\mathrm{al}^{46}$ reported in 2005 that the overall sensitivity was $59 \%$ using the 16-row CT.

The Society of Cardiovascular Computed Tomography guidelines recommend to use a CT scanner with 64 rows 
or more. ${ }^{47}$ Although the sensitivity and negative predictive value of coronary $\mathrm{CT}$ angiography by using 64-row $\mathrm{CT}$ is good, ${ }^{1,48-50}$ the accuracy is reduced in patients with high heart rates. ${ }^{2}$ The right coronary artery is especially affected by motion artifacts. ${ }^{48}$ An optimal heart rate to obtain a diagnostic image quality using 64-row $\mathrm{CT}$ was reported as $<65 \mathrm{bpm}^{2,3}$

Recently, scanners that cover the entire heart in one rotation have become available. Because wide area coverage does not directly increase the temporal resolution, the initial 320-row CT requires a heart rate lower than $65 \mathrm{bpm}$ for optimal image quality. ${ }^{3}$ The latest 320 -row CT increased the gantry rotation time up to $275 \mathrm{~ms}$; thus, optimal image quality could be obtained up to $75 \mathrm{bpm} .{ }^{51}$

Low heart rate is important for decreasing the radiation exposure, especially in high-end scanners. In patients with high heart rates, multiple heartbeat acquisition using 320-row CT is necessary, which simply doubles or triples the radiation dose. ${ }^{51}$ When one beat acquisition during end diastole is achieved, the average radiation dose could be as low as $1-2 \mathrm{mSv}^{51-53}$ and even a submillisievert radiation dose could be achieved if low tube potential is used. ${ }^{54}$ The latest dual-source scanners have a temporal resolution of $75 \mathrm{~ms}$ with a gantry rotation time of $280 \mathrm{~ms} .^{55} \mathrm{~A}$ radiation dose of approximately $1 \mathrm{mSv}$ could be achieved in high-pitch spiral helical acquisition, ${ }^{56,57}$ but the image quality would reduce when the heart rate is higher than $65 \mathrm{bpm} .{ }^{55}$

In 64-row CT, a vendor-specific motion-correction algorithm is available to improve the coronary artery image quality and the diagnosis of CAD. ${ }^{58-61}$ This algorithm uses scan data from adjacent cardiac phases within a single cardiac cycle to correct for the beating motion of the coronary arteries. This algorithm is superior to multi-segment reconstruction, which uses data from adjacent heartbeats, because the heart does not follow the same pattern of motion with every heartbeat. ${ }^{62-64}$ Although this is a promising method for patients with high heart rates, data of cardiac phase before and after the reconstruction phase need to be acquired, which leads to excessive radiation exposure. For these reasons, a heart rate lower than $65 \mathrm{bpm}$ is important to maintain the image quality with a low radiation dose of coronary CT angiography in conventional and high-end scanners.

\section{Effects of landiolol on heart rate during coronary CT angiography}

Landiolol could be injected continuously or by a bolus manner. Continuous injection of landiolol at $0.036 \mathrm{mg} / \mathrm{kg} / \mathrm{min}$ resulted in a decrease in heart rate of $16 \mathrm{bpm}$, which recovered
15 minutes after the cessation of injection (Table 1$) \cdot{ }^{65} \mathrm{~A}$ bolus injection of landiolol at $0.125 \mathrm{mg} / \mathrm{kg}$ decreased the heart rate by $11.7 \mathrm{bpm}$ at $3-5$ minutes after the injection, which resumed to the initial heart rate at 7 minutes. ${ }^{7}$ The target heart rate of $65 \mathrm{bpm}$ was achieved in $50 \%$ of the patients with an initial heart rate between 70 and $90 \mathrm{bpm} .^{7}$ Another study that assessed the difference in the reduction of heart rate between landiolol and propranolol showed that a bolus dose of $0.125 \mathrm{mg} / \mathrm{kg}$ of landiolol decreased the heart rate by $8.8 \mathrm{bpm}$, which was slightly inferior to $10-20 \mathrm{mg}$ of oral propranolol that reduced the heart rate by $11 \mathrm{bpm} .{ }^{66}$

Hirano et al ${ }^{67}$ assessed the reductive effects of different doses of landiolol on heart rate during coronary $\mathrm{CT}$ angiography. Compared with a bolus injection of $0.125 \mathrm{mg} / \mathrm{kg}$, increased doses of $0.25 \mathrm{mg} / \mathrm{kg}$ and $0.50 \mathrm{mg} / \mathrm{kg}$ resulted in greater reduction of heart rate than that by $0.125 \mathrm{mg} / \mathrm{kg}$ injection (Table 1). The target heart rate of $65 \mathrm{bpm}$ was achieved in $58.6 \%, 60.7 \%$, and $63.3 \%$ of the patients in groups of 0.125 , 0.25 , and $0.50 \mathrm{mg} / \mathrm{kg}$ injection, respectively. The authors concluded that using high-dose $(0.5 \mathrm{mg} / \mathrm{kg})$ landiolol had little effect on image quality because the heart rate during the scan was within $2 \mathrm{bpm}$ between the three groups. However, the heart rate reduction in the high-dose group $(0.5 \mathrm{mg} / \mathrm{kg})$ was $5 \mathrm{bpm}$ more than that in the remaining groups, which could be promising for patients with high heart rates.

Nakamura et $\mathrm{al}^{66}$ investigated the effects of using additional landiolol (Table 1). By adding $3.75 \mathrm{mg} / \mathrm{kg}$ of landiolol, the heart rate was reduced by $4 \mathrm{bpm}$ more than that in the $0.125 \mathrm{mg} / \mathrm{kg}$ injection group.

Oral $\beta$-blockers are occasionally prescribed for patients with high heart rates prior to the scanning. ${ }^{6}$ Landiolol is also effective to further reduce the heart rate in patients who did not achieve the target heart rate in spite of taking oral $\beta$-blocker as a premedication. Bolus injection of $0.125 \mathrm{mg} / \mathrm{kg}$ landiolol reduced the heart rate by $9 \mathrm{bpm}$ in patients who received $20-40 \mathrm{mg}$ of oral metoprolol ahead of the scan (Table 1). ${ }^{18}$

\section{Effects of landiolol on image quality and diagnosis of CAD}

A study using a 16-row CT scanner with a continuous injection of $0.036 \mathrm{mg} / \mathrm{kg} / \mathrm{min}$ of landiolol showed that $94 \%$ of the segments had excellent or good image quality, with per-artery sensitivity, specificity, positive predictive value, and negative predictive value of $94 \%, 98 \%, 92 \%$, and $100 \%$, respectively ${ }^{65}$ Similarly, a bolus injection of $0.125 \mathrm{mg} / \mathrm{kg}$ landiolol resulted in $96.3 \%{ }^{7}$ and $98.5 \%{ }^{18}$ of the total segments as diagnostic using a 16- and 64-row CT scanner, respectively. ${ }^{7}$ 
Table I Effectiveness of landiolol protocols during coronary CT angiography

\begin{tabular}{|c|c|c|c|c|c|}
\hline Study & $\mathbf{N}$ & Landiolol protocol & $\begin{array}{l}\text { Initial heart } \\
\text { rate (bpm) }\end{array}$ & $\begin{array}{l}\text { Heart rate during } \\
\text { scan (bpm) }\end{array}$ & $\begin{array}{l}\text { Heart rate } \\
\text { reduction }(\mathrm{bpm})\end{array}$ \\
\hline Isobe et $\mathrm{a}^{65}$ & 133 & Infusion pump $0.036 \mathrm{mg} / \mathrm{kg} / \mathrm{min}$ & $67.1 \pm 7.4$ & $51.8 \pm 3.6$ & 15.3 \\
\hline Hirano et $\mathrm{al}^{7}$ & 39 & Bolus injection $0.125 \mathrm{mg} / \mathrm{kg}$ & $77.1 \pm 9.8$ & $65.4 \pm 8.0$ & 11.7 \\
\hline \multirow[t]{2}{*}{ Nakamura et al ${ }^{66}$} & 188 & Bolus injection $0.125 \mathrm{mg} / \mathrm{kg}$ & $72.9 \pm 7.3$ & $64.1 \pm 7.4$ & $8.8 \pm 5.7$ \\
\hline & 92 & Bolus injection $0.125 \mathrm{mg} / \mathrm{kg}+3.75 \mathrm{mg}$ & $79.7 \pm 4.1$ & $67.2 \pm 6.9$ & $12.5 \pm 6.1$ \\
\hline \multirow[t]{3}{*}{ Hirano et a ${ }^{67}$} & 29 & Bolus injection $0.125 \mathrm{mg} / \mathrm{kg}$ & $76.2 \pm 12.1$ & $63.9 \pm 7.8$ & $15.6 \pm 6.6$ \\
\hline & 28 & Bolus injection $0.25 \mathrm{mg} / \mathrm{kg}$ & $75.8 \pm 9.2$ & $64.0 \pm 8.1$ & $16.5 \pm 7.8$ \\
\hline & 30 & Bolus injection $0.5 \mathrm{mg} / \mathrm{kg}$ & $80.1 \pm 11.0$ & $62.8 \pm 9.4$ & $21.5 \pm 6.1$ \\
\hline Osawa et $\mathrm{al}^{18, \mathrm{a}}$ & 66 & Bolus injection $0.125 \mathrm{mg} / \mathrm{kg}$ & $76 \pm 10$ & $67 \pm 10$ & 9 \\
\hline
\end{tabular}

Notes: ${ }^{\mathrm{a}}$ Oral metoprolol $20-40 \mathrm{mg}$ as premedication. Data are presented as mean \pm standard deviation.

Abbreviations: bpm, beats per minute; CT, computed tomography.

One study compared the image quality between low-dose $(0.125 \mathrm{mg} / \mathrm{kg})$ and high-dose $(0.125 \mathrm{mg} / \mathrm{kg}$ with additional $3.75 \mathrm{mg}$ ) landiolol. High-dose landiolol reduced segments with a nondiagnostic image quality from $42 \%$ to $22 \%$ when the initial heart rate was higher than $75 \mathrm{bpm} .{ }^{66}$

Another study compared the image quality in coronary CT angiography between patients with a bolus injection of $0.125,0.25$, and $0.5 \mathrm{mg} / \mathrm{kg}$ landiolol by using a 32-row scanner. ${ }^{67}$ Although the reduction in heart rate was highest in the $0.5 \mathrm{mg} / \mathrm{kg}$ group, the image quality did not significantly differ. This was mainly because the heart rate was quite similar $(<2 \mathrm{bpm})$ between the three groups.

\section{Protocols for administration of landiolol during coronary CT angiography}

Landiolol could be injected continuously or as a bolus injection. In a study using a 16-row CT scanner, landiolol was continuously injected at a starting dose of $0.02 \mathrm{mg} / \mathrm{kg} / \mathrm{min}$, which was increased until the target heart rate of $55 \mathrm{bpm}$ was achieved. ${ }^{65}$ However, in many studies, landiolol was administered at $0.125 \mathrm{mg} / \mathrm{kg}$ in 1 minute, which is recommended in the product document in Japan. ${ }^{7,18,67,68}$ Considering that the heart rate after intravenous administration of landiolol is lowest between 4 and 7 minutes after injection, coronary CT angiography should be performed within this time., ${ }^{78}$
Figure 2 shows a diagram for the use of landiolol in coronary CT angiography. Oral $\beta$-blockers such as metoprolol or propranolol should be administered approximately 1-2 hours prior to the examination if the heart rate is high at the outpatient department. Measurement of the heart rate and blood pressure is performed on arrival. Sublingual nitrate is administered in order to improve the visibility of coronary arteries and the diagnosis of CAD. ${ }^{69-71}$ Nitrates should be administered at least 3 minutes, but no longer than 15 minutes, before acquisition. ${ }^{72}$ Prior to the coronary CT angiography examination, an electrocardiogram-gated cardiac scan without contrast medium is performed in order to evaluate the coronary calcium level. ${ }^{73}$ Following the calcium scoring scan, $0.125 \mathrm{mg} / \mathrm{kg}$ landiolol would be injected intravenously in 1 minute. The coronary $\mathrm{CT}$ angiography acquisition needs to be performed within approximately 4-7 minutes after the bolus injection of landiolol. ${ }^{718}$ The heart rate and blood pressure should be checked again before leaving the CT room.

\section{Safety}

In order to prevent the adverse effects of $\beta$-blockers, practitioners need to know about the contraindications and side effects of $\beta$-blockers in general (Table 2). ${ }^{5,74}$ Serious side effects may occur, especially when $\beta$-blockers are used in large doses. Hence, if the contraindications in Table 2 are ruled out, side effects using landiolol are rare. ${ }^{7}$

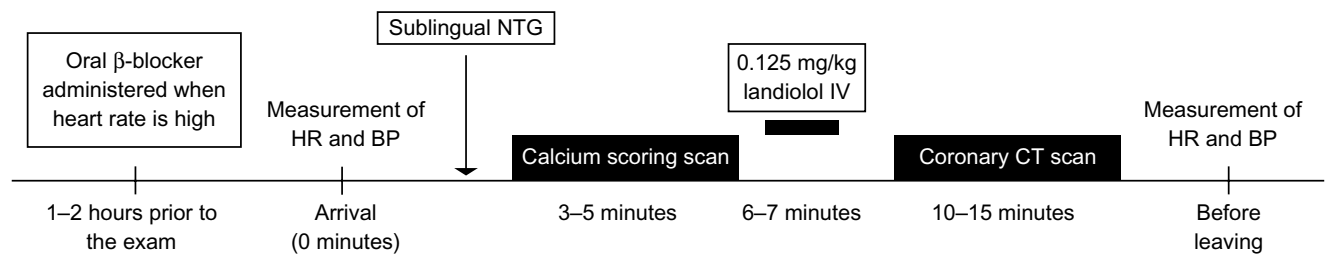

Figure 2 Diagram of the usage of landiolol during coronary CT angiography.

Abbreviations: BP, blood pressure; HR, heart rate; NTG, nitroglycerin; CT, computed tomography; IV, intravenous. 
Table 2 Adverse effects and contraindications of $\beta$-blockers in general ${ }^{5,74}$

\begin{tabular}{ll}
\hline Cardiovascular & Bradycardia \\
& Atrioventricular block \\
& Raynaud's phenomenon \\
& Symptomatic hypotension \\
& Severe decompensated cardiac failure \\
Pulmonary & Asthma \\
& Bronchospastic chronic obstructive \\
& pulmonary disease \\
Drug interactions & Decrease absorption \\
& Aluminum salts, cholestyramine, colestipol \\
& Decrease plasma concentration \\
& Alcohol, phenytoin, rifampicin, \\
& phenobarbital, smoking \\
Increase the bioavailability \\
Cimetidine, hydralazine \\
Depress sinus-node function \\
Verapamil, diltiazem \\
Fatigue \\
Headache \\
Sleep disturbance \\
Insomnia \\
Depression
\end{tabular}

\section{Bradycardia}

A study with 188 patients using a bolus of $0.125 \mathrm{mg} / \mathrm{kg}$ landiolol resulted in one patient with bradycardia (40 bpm), who recovered after 5 minutes without any medication. ${ }^{66}$ However, bradycardia was not reported in other studies that used landiolol injection of $0.125-0.5 \mathrm{mg} / \mathrm{kg} .{ }^{7,18,65,67}$ When continuous injection between 3 and $5 \mu \mathrm{g} / \mathrm{kg} / \mathrm{min}$ was used to control the heart rate after cardiac surgery, ten of 68 patients experienced bradycardia (heart rate $<50 \mathrm{bpm}$ ), which recovered after cessation of drug infusion and administration of a cardiotonic agent. ${ }^{15}$

\section{Hypotension}

Hypotension is a rare side effect when a bolus injection of $0.125 \mathrm{mg} / \mathrm{kg}$ landiolol is used, ${ }^{7,18,67}$ although Nakamura et $\mathrm{al}^{66}$ reported hypotension $(86 / 55 \mathrm{mmHg})$ in one out of 188 patients, which recovered after 10 minutes. Another study reported that one of 28 patients who received 0.25 $\mathrm{mg} / \mathrm{kg}$ landiolol had mild hypotension, which resolved without any treatment. ${ }^{67}$ When landiolol is continuously injected, hypotension is rare up to $36 \mu \mathrm{g} / \mathrm{kg} / \mathrm{min} .{ }^{14,35,65,75}$ Special attention is necessary when a landiolol dose higher than $0.2 \mathrm{mg} / \mathrm{kg}$ is used because hypotension is occasionally reported at this dosage. ${ }^{20,28}$ Moreover, patients with an ejection fraction $<50 \%$ could be at risk of hypotension. ${ }^{76}$

\section{Left ventricular dysfunction}

No studies have assessed the safety of landiolol during coronary CT angiography in patients with severe left ventricular dysfunction. The J-Land study tested the effect of landiolol for controlling atrial fibrillation and atrial flutter with severe left ventricular dysfunction (left ventricular ejection fraction of $25 \%-50 \%) .{ }^{77}$ A continuous injection of $1-10 \mu \mathrm{g} /$ $\mathrm{kg} / \mathrm{min}$ resulted in severe adverse events in two patients (congestive heart failure and embolic stroke). Currently, the safety of landiolol is not tested in patients with ejection fractions $<25 \%$.

\section{Bronchospasm}

Currently, the use of landiolol has not been reported in patients with asthma because asthma is also contraindicated for iodinated contrast medium. ${ }^{78}$ A study investigated the theoretical bronchospastic effects of landiolol by using a compartment model. The results indicated that the reduction in forced expiratory volume in 1 second would be below $3 \%$ during coronary CT angiography scan when $0.125 \mathrm{mg} /$ $\mathrm{kg}$ landiolol was injected. ${ }^{79}$ Therefore, the possibility that landiolol would cause bronchospasm is small.

\section{Anaphylactoid reaction}

Previous studies have raised concern for an increase in anaphylactoid reaction from contrast medium in patients receiving $\beta$-blockers. ${ }^{80,81}$ These agents might impede treatment effectiveness of epinephrine. ${ }^{82}$ However, landiolol is advantageous over other $\beta$-blockers because of its short half-life. Even when an anaphylactoid reaction occurs, epinephrine would be effective in a few minutes.

\section{Other side effects}

Other reported side effects of landiolol are as follows: increase in alanine aminotransferase level; increase in aspartate aminotransferase level; reduction in blood platelet counts; and increase in $\gamma$-glutamic acid transferase level. ${ }^{67}$ All adverse events resolved without any treatment.

\section{Cost-effectiveness}

Igarashi et al ${ }^{83}$ performed a cost-minimization analysis of landiolol usage in coronary CT angiography. The authors hypothesized that landiolol could reduce nondiagnostic coronary CT studies by achieving an optimal heart rate. The study reported that landiolol could reduce the cost by JPY 3,292 per patient, with an overall medical cost savings of JPY 54 million due to the reduction in unnecessary coronary arteriogram. 


\section{Conclusion}

In summary heart rate less than $65 \mathrm{bpm}$ is important to maintain the image quality with a low radiation dose in coronary CT angiography using conventional and highend scanners. Landiolol is an ideal $\beta$-blocker for coronary CT angiography because of its high cardioselectivity ( $\beta 1 /$ $\beta 2=255$ ) and short half-life ( 4 minutes) and it could be used with other oral $\beta$-blocker premedications. A bolus injection of $0.125 \mathrm{mg} / \mathrm{kg}$ would decrease the heart rate by approximately 10-15 bpm within 4-7 minutes after injection. Adverse effects of landiolol are rare, but the heart rate and blood pressure of patients should be checked before and after coronary CT scanning.

\section{Disclosure}

The authors report no conflicts of interest in this work.

\section{References}

1. Miller JM, Rochitte CE, Dewey M, et al. Diagnostic performance of coronary angiography by 64-row CT. $N$ Engl J Med. 2008;359(22): 2324-2336.

2. Husmann L, Valenta I, Gaemperli O, et al. Feasibility of low-dose coronary CT angiography: first experience with prospective ECGgating. Eur Heart J. 2008;29(2):191-197.

3. Fujimoto $\mathrm{S}$, Matsutani $\mathrm{H}$, Kondo $\mathrm{T}$, et al. Image quality and radiation dose stratified by patient heart rate for coronary 64- and 320-MDCT angiography. AJR Am J Roentgenol. 2013;200(4):765-770.

4. Abbara S, Arbab-Zadeh A, Callister TQ, et al. SCCT guidelines for performance of coronary computed tomographic angiography: a report of the Society of Cardiovascular Computed Tomography Guidelines Committee. J Cardiovasc Comput Tomogr. 2009;3(3):190-204.

5. Mahabadi AA, Achenbach S, Burgstahler C, et al; Working group "Cardiac CT" of the German Cardiac Society. Safety, efficacy, and indications of beta-adrenergic receptor blockade to reduce heart rate prior to coronary CT angiography. Radiology. 2010;257(3):614-623.

6. Pannu HK, Sullivan C, Lai S, Fishman EK. Evaluation of the effectiveness of oral beta-blockade in patients for coronary computed tomographic angiography. J Comput Assist Tomogr. 2008;32(2):247-251.

7. Hirano M, Yamashina A, Hara K, et al; Landiolol Hydrochloride Study Group. A multicenter, open-label study of an intravenous short-acting $\beta 1$-adrenergic receptor antagonist landiolol hydrochloride for coronary computed tomography angiography by 16 -slice multi-detector computed tomography in Japanese patients with suspected ischemic cardiac disease. Drugs R D. 2014;14(3):185-194.

8. Nakashima M, Kanemaru M. [Phase I study of ONO-1101, a new ultra short acting b1-blocking agent in healthy volunteers]. Journal of Clinical Therapeutics and Medicine. 2000;16:1531-1556. Japanese.

9. Sakamoto A, Hamasaki T, Kitakaze M. Perioperative landiolol administration reduces atrial fibrillation after cardiac surgery: a meta-analysis of randomized controlled trials. Adv Ther. 2014;31(4):440-450.

10. Sasao J, Tarver SD, Kindscher JD, Taneyama C, Benson KT, Goto H. In rabbits, landiolol, a new ultra-short-acting beta-blocker, exerts a more potent negative chronotropic effect and less effect on blood pressure than esmolol. Can J Anaesth. 2001;48(10):985-989.

11. Jin SK, Chung HJ, Chung MW, et al. Influence of CYP2D6*10 on the pharmacokinetics of metoprolol in healthy Korean volunteers. $J$ Clin Pharm Ther. 2008;33(5):567-573.

12. Smith C, Teitler M. Beta-blocker selectivity at cloned human beta 1and beta 2-adrenergic receptors. Cardiovasc Drugs Ther. 1999;13(2): $123-126$.
13. Erhardt PW, Woo CM, Anderson WG, Gorczynski RJ. Ultra-short-acting beta-adrenergic receptor blocking agents. 2. (Aryloxy) propanolamines containing esters on the aryl function. $J$ Med Chem. 1982;25(12): $1408-1412$.

14. Maisawa K, Yamazaki K, Ishitoya H, Shimamura Y. Effect of landiolol hydrochloride after off-pump coronary artery bypass. Asian Cardiovasc Thorac Ann. 2013;21(2):170-175.

15. Ogawa S, Okawa Y, Goto Y, Aoki M, Baba H. Perioperative use of a beta blocker in coronary artery bypass grafting. Asian Cardiovasc Thorac Ann. 2013;21(3):265-269.

16. Maurovich-Horvat $\mathrm{P}$, Károlyi $\mathrm{M}$, Horváth $\mathrm{T}$, et al. Esmolol is noninferior to metoprolol in achieving a target heart rate of 65 beats $/ \mathrm{min}$ in patients referred to coronary $\mathrm{CT}$ angiography: a randomized controlled clinical trial. J Cardiovasc Comput Tomogr. 2015;9(2):139-145.

17. Tsuchiya H, Mizogami M. Characteristic interactivity of landiolol, an ultra-short-acting highly selective $\beta 1$-blocker, with biomimetic membranes: comparisons with $\beta 1$-selective esmolol and non-selective propranolol and alprenolol. Front Pharmacol. 2013;4:150.

18. Osawa K, Miyoshi T, Sato S, et al. Safety and efficacy of a bolus injection of landiolol hydrochloride as a premedication for multidetector-row computed tomography coronary angiography. Circ J. 2013;77(1): 146-152.

19. Iguchi S, Iwamura H, Nishizaki M, et al. Development of a highly cardioselective ultra short-acting beta-blocker, ONO-1101. Chem Pharm Bull (Tokyo). 1992;40(6):1462-1469.

20. Sugiyama A, Takahara A, Hashimoto K. Electrophysiologic, cardiohemodynamic and beta-blocking actions of a new ultra-short-acting betablocker, ONO-1101, assessed by the in vivo canine model in comparison with esmolol. J Cardiovasc Pharmacol. 1999;34(1):70-77.

21. Jacobs JR, Maier GW, Rankin JS, Reves JG. Esmolol and left ventricular function in the awake dog. Anesthesiology. 1988;68(3):373-378.

22. Murthy VS, Hwang TF, Zagar ME, Vollmer RR, Schmidt DH. Cardiovascular pharmacology of ASL-8052, an ultra-short acting beta blocker. Eur J Pharmacol. 1983;94(1-2):43-51.

23. Reilly CS, Wood M, Koshakji RP, Wood AJ. Ultra-short-acting beta-blockade: a comparison with conventional beta-blockade. Clin Pharmacol Ther. 1985;38(5):579-585.

24. Atarashi H, Kuruma A, Yashima M, et al. Pharmacokinetics of landiolol hydrochloride, a new ultra-short-acting beta-blocker, in patients with cardiac arrhythmias. Clin Pharmacol Ther. 2000;68(2):143-150.

25. Ogata J, Yokoyama T, Okamoto T, Minami K. Managing a tachyarrhythmia in a patient with pheochromocytoma with landiolol, a novel ultrashort-acting beta-adrenergic blocker. Anesth Analg. 2003;97(1): 294-295.

26. Nishina K, Mikawa K, Yonemoto Y, Sugimoto Y. The efficacy of bolus administration of landiolol for attenuating tachycardia in pheochromocytoma. Anesth Analg. 2004;98(3):876-877.

27. Yamazaki A, Kinoshita H, Shimogai M, et al. Landiolol attenuates tachycardia in response to endotracheal intubation without affecting blood pressure. Can J Anaesth. 2005;52(3):254-257.

28. Harasawa R, Hayashi Y, Iwasaki M, Kamibayashi T, Mashimo T. Bolus administration of landiolol, a short-acting, selective beta1blocker, to treat tachycardia during anesthesia: a dose-dependent study. J Cardiothorac Vasc Anesth. 2006;20(6):793-795.

29. Shirasaka T, Iwasaki T, Hosokawa N, Komatsu M, Kasaba T, Takasaki M. Effects of landiolol on the cardiovascular response during tracheal extubation. J Anesth. 2008;22(3):322-325.

30. Sezai A, Osaka S, Yaoita H, et al. Safety and efficacy of landiolol hydrochloride for prevention of atrial fibrillation after cardiac surgery in patients with left ventricular dysfunction: Prevention of Atrial Fibrillation After Cardiac Surgery With Landiolol Hydrochloride for Left Ventricular Dysfunction (PLATON) trial. J Thorac Cardiovasc Surg. 2015;150(4):957-964.

31. Fujiwara H, Sakurai M, Namai A, Kawamura T. Effect of low-dose landiolol, an ultrashort-acting beta-blocker, on postoperative atrial fibrillation after CABG surgery. Gen Thorac Cardiovasc Surg. 2009;57(3):132-137. 
32. Sezai A, Minami K, Nakai T, et al. Landiolol hydrochloride for prevention of atrial fibrillation after coronary artery bypass grafting: new evidence from the PASCAL trial. J Thorac Cardiovasc Surg. 2011;141(6):1478-1487.

33. Ito N, Tashiro T, Morishige N, et al. Safety and efficacy of an ultrashortacting $\beta 1$-blocker on left ventricular dysfunction. Heart Surg Forum. 2012;15(4):E189-E194.

34. Morishima A, Hirao S, Nagasaka S, Yokoyama S, Kaneda K, Nishiwaki N. [Suppressive effect of landiolol hydrochloride on atrial fibrillation following surgical repair of acute type A aortic dissection]. Japanese Journal of Vascular Surgery. 2009;18:481-485.

35. Sakaguchi M, Sasaki Y, Hirai H, et al. Efficacy of landiolol hydrochloride for prevention of atrial fibrillation after heart valve surgery. Int Heart J. 2012;53(6):359-363.

36. Sakamoto A, Kitakaze M, Takamoto S, Namiki A, Kasanuki H, Hosoda S; JL-KNIGHT study group. Landiolol, an ultra-short-acting $\beta_{1}$-blocker, more effectively terminates atrial fibrillation than diltiazem after open heart surgery: prospective, multicenter, randomized, open-label study (JL-KNIGHT study). Circ J. 2012;76(5):1097-1101.

37. Hanada K, Higuma T, Nishizaki F, et al. Randomized study on the efficacy and safety of landiolol, an ultra-short-acting $\beta 1$-adrenergic blocker, in patients with acute myocardial infarction undergoing primary percutaneous coronary intervention. Circ J. 2012;76(2):439-445.

38. Boere E, Birkenhäger TK, Groenland TH, van den Broek WW. Betablocking agents during electroconvulsive therapy: a review. Br JAnaesth. 2014;113(1):43-51.

39. Saito S. Anesthesia management for electroconvulsive therapy: hemodynamic and respiratory management. J Anesth. 2005;19(2):142-149.

40. Sakamoto A, Ogawa R, Suzuki H, Kimura M, Okubo Y, Fujiya T. Landiolol attenuates acute hemodynamic responses but does not reduce seizure duration during maintenance electroconvulsive therapy. Psychiatry Clin Neurosci. 2004;58(6):630-635.

41. Saito S, Nishihara F, Akihiro T, et al. Landiolol and esmolol prevent tachycardia without altering cerebral blood flow. Can J Anaesth. 2005;52(10):1027-1034.

42. Ide M, Kadoi Y, Saito S, et al. Effects of landiolol on left ventricular function during electroconvulsive therapy: a transthoracic echocardiographic study. J Anesth. 2010;24(2):272-276.

43. Matsura M, Fujiwara Y, Ito H, et al. Prolongation of QT interval induced by electroconvulsive therapy is attenuated by landiolol. JECT. 2010;26(1):37-40

44. Nomoto K, Suzuki T, Serada K, Oe K, Yoshida T, Yamada S. Effects of landiolol on hemodynamic response and seizure duration during electroconvulsive therapy. J Anesth. 2006;20(3):183-187.

45. Giesler T, Baum U, Ropers D, et al. Noninvasive visualization of coronary arteries using contrast-enhanced multidetector CT: influence of heart rate on image quality and stenosis detection. AJR Am J Roentgenol. 2002;179(4):911-916.

46. Heuschmid M, Kuettner A, Schroeder S, et al. ECG-gated 16-MDCT of the coronary arteries: assessment of image quality and accuracy in detecting stenoses. Am J Roentgenol. 2005;184(5):1413-1419.

47. Raff GL, Chinnaiyan KM, Cury RC, et al; Society of Cardiovascular Computed Tomography Guidelines Committee. SCCT guidelines on the use of coronary computed tomographic angiography for patients presenting with acute chest pain to the emergency department: a report of the Society of Cardiovascular Computed Tomography Guidelines Committee. J Cardiovasc Comput Tomogr. 2014;8(4):254-271.

48. Pugliese F, Mollet NR, Runza G, et al. Diagnostic accuracy of noninvasive 64-slice CT coronary angiography in patients with stable angina pectoris. Eur Radiol. 2006;16(3):575-582.

49. Budoff MJ, Dowe D, Jollis JG, et al. Diagnostic performance of 64-multidetector row coronary computed tomographic angiography for evaluation of coronary artery stenosis in individuals without known coronary artery disease: results from the prospective multicenter ACCURACY (Assessment by Coronary Computed Tomographic Angiography of Individuals Undergoing Invasive Coronary Angiography) trial. J Am Coll Cardiol. 2008;52(21):1724-1732.
50. Mollet NR, Cademartiri F, van Mieghem CA, et al. High-resolution spiral computed tomography coronary angiography in patients referred for diagnostic conventional coronary angiography. Circulation. 2005;112(15):2318-2323.

51. Tomizawa N, Maeda E, Akahane M, Torigoe R, Kiryu S, Ohtomo K. Coronary CT angiography using the second-generation 320-detector row $\mathrm{CT}$ : assessment of image quality and radiation dose in various heart rates compared with the first-generation scanner. Int J Cardiovasc Imaging. 2013;29(7):1613-1618.

52. Wong DT, Soh SY, Ko BS, et al. Superior CT coronary angiography image quality at lower radiation exposure with second generation 320-detector row CT in patients with elevated heart rate: a comparison with first generation 320-detector row CT. Cardiovasc Diagn Ther. 2014;4(4):299-306.

53. Tomizawa N, Kanno S, Maeda E, Akahane M, Torigoe R, Ohtomo K. Minimizing the acquisition phase in coronary $\mathrm{CT}$ angiography using the second generation 320-row CT. Jpn J Radiol. 2014;32(7):391-396.

54. Chen MY, Shanbhag SM, Arai AE. Submillisievert median radiation dose for coronary angiography with a second-generation 320 detector row CT scanner in 107 consecutive patients. Radiology. 2013;267(1):76-85.

55. Bogaard K, van der Zant FM, Knol RJ, et al. High-pitch prospective ECG-triggered helical coronary computed tomography angiography in clinical practice: image quality and radiation dose. Int J Cardiovasc Imaging. 2015;31(1):125-133.

56. Achenbach S, Marwan M, Ropers D, et al. Coronary computed tomography angiography with a consistent dose below $1 \mathrm{mSv}$ using prospectively electrocardiogram-triggered high-pitch spiral acquisition. Eur Heart J. 2010;31(3):340-346.

57. Sun K, Han RJ, Cui LF, et al. Feasibility and diagnostic accuracy for assessment of coronary artery stenosis of prospectively electrocardiogram-gated high-pitch spiral acquisition mode dual-source CT coronary angiography in patients with relatively higher heart rates: in comparison with catheter coronary angiography. Chin Med Sci J. 2013;27(4):213-219.

58. Leipsic J, Labounty TM, Hague CJ, et al. Effect of a novel vendorspecific motion-correction algorithm on image quality and diagnostic accuracy in persons undergoing coronary CT angiography without rate-control medications. J Cardiovasc Comput Tomogr. 2012;6(3): $164-171$.

59. Li Q, Li P, Su Z, et al. Effect of a novel motion correction algorithm (SSF) on the image quality of coronary CTA with intermediate heart rates: segment-based and vessel-based analyses. Eur J Radiol. 2014;83(11):2024-2032.

60. Fuchs TA, Stehli J, Dougoud S, et al. Impact of a new motion-correction algorithm on image quality of low-dose coronary CT angiography in patients with insufficient heart rate control. Acad Radiol. 2014;21(3): 312-317.

61. Lee H, Kim JA, Lee JS, Suh J, Paik SH, Park JS. Impact of a vendorspecific motion-correction algorithm on image quality, interpretability, and diagnostic performance of daily routine coronary CT angiography: influence of heart rate on the effect of motion-correction. Int $J$ Cardiovasc Imaging. 2014;30(8):1603-1612.

62. Tomizawa N, Komatsu S, Akahane M, Torigoe R, Kiryu S, Ohtomo K Relationship between beat to beat coronary artery motion and image quality in prospectively ECG-gated two heart beat 320-detector row coronary CT angiography. Int J Cardiovasc Imaging. 2012;28(1): $139-146$.

63. Halliburton SS, Stillman AE, Flohr T, et al. Do segmented reconstruction algorithms for cardiac multi-slice computed tomography improve image quality? Herz. 2003;28(1):20-31.

64. Flohr T, Ohnesorge B. Heart rate adaptive optimization of spatial and temporal resolution for electrocardiogram-gated multislice spiral CT of the heart. J Comput Assist Tomogr. 2001;25(6):907-923.

65. Isobe $\mathrm{S}$, Sato K, Sugiura K, et al. Use of landiolol hydrochloride, a new beta-blocker, in coronary computed tomography angiography. Int $J$ Cardiol. 2010;139(2):196-198. 
66. Nakamura Y, Yamaji K, Saho T, et al. A comparison of bolus injection of landiolol versus oral administration of propranolol before cardiac computed tomography. Springerplus. 2014;3:93.

67. Hirano M, Hara K, Ikari Y, et al. Dose-finding study of landiolol hydrochloride: a short-acting $\beta 1$-blocker for controlling heart rate during coronary computed-tomography angiography in Japan. Adv Ther. 2013;30(9):803-818.

68. [Product document of COREBETA] [webpage on the internet]. KEGG; 2015. Available from: http://www.kegg.jp/medicus-bin/japic_med_ product?id=00059754-001\#00059754-001. Accessed August 16, 2015. Japanese.

69. Dewey M, Hoffmann H, Hamm B. Multislice CT coronary angiography: effect of sublingual nitroglycerine on the diameter of coronary arteries. Rofo. 2006;178(6):600-604.

70. Sato K, Isobe S, Sugiura K, et al. Optimal starting time of acquisition and feasibility of complementary administration of nitroglycerin with intravenous beta-blocker in multislice computed tomography. J Comput Assist Tomogr. 2009;33(2):193-198.

71. Chun EJ, Lee W, Choi YH, et al. Effects of nitroglycerin on the diagnostic accuracy of electrocardiogram-gated coronary computed tomography angiography. J Comput Assist Tomogr. 2008;32(1):86-92.

72. Terashima M, Meyer CH, Keeffe BG, et al. Noninvasive assessment of coronary vasodilation using magnetic resonance angiography. $\mathrm{J} \mathrm{Am}$ Coll Cardiol. 2005;45(1):104-110.

73. Agatston AS, Janowitz WR, Hildner FJ, Zusmer NR, Viamonte M Jr, Detrano R. Quantification of coronary artery calcium using ultrafast computed tomography. J Am Coll Cardiol. 1990;15(4):827-832.

74. López-Sendón J, Swedberg K, McMurray J, et al; Task ForceOn Beta-Blockers of the European Society of Cardiology. Expert consensus document on beta-adrenergic receptor blockers. Eur Heart J. 2004;25(15):1341-1362.
75. Hoshi T, Sato A, Nishina H, et al. Acute hemodynamic effects of landiolol, an ultra-short-acting beta-blocker, in patients with acute coronary syndrome: preliminary study. J Cardiol. 2012;60(4):252-256.

76. Goto K, Shingu C, Miyamoto S, Miyakawa H, Noguchi T. The effect of landiolol on hemodynamics and left ventricular function in patients with coronary artery disease. J Clin Anesth. 2007;19(7):523-529.

77. Nagai R, Kinugawa K, Inoue H, et al; J-Land Investigators. Urgent management of rapid heart rate in patients with atrial fibrillation/flutter and left ventricular dysfunction: comparison of the ultra-short-acting $\beta 1$-selective blocker landiolol with digoxin (J-Land Study). Circ J. 2013;77(4):908-916.

78. Pradubpongsa P, Dhana N, Jongjarearnprasert K, Janpanich S, Thongngarm T. Adverse reactions to iodinated contrast media: prevalence, risk factors and outcome-the results of a 3-year period. Asian Pac J Allergy Immunol. 2013;31(4):299-306.

79. Fujito K, Takayanagi R, Kimura K, Yokoyama H, Yamada Y. Evaluation of clinical bradycardiac effect and respiratory adverse effect of $\beta$-blocking agents in coronary computed tomography angiography based on theoretical analysis. Eur J Drug Metab Pharmacokinet. Epub 2014 Dec 16.

80. Lang DM, Alpern MB, Visintainer PF, Smith ST. Increased risk for anaphylactoid reaction from contrast media in patients on beta-adrenergic blockers or with asthma. Ann Intern Med. 1991;115(4):270-276.

81. Kemp SF, Lockey RF. Anaphylaxis: a review of causes and mechanisms. J Allergy Clin Immunol. 2002;110(3):341-348.

82. ESUR Guidelines on Contrast Media [webpage on the Internet]. European Society of Urogenital Radiology; 2012. Available from: http:// www.esur.org/guidelines/jp/index.php. Accessed September 3, 2015.

83. Igarashi A, Fujito K, Hirano M, Fukuda T. Cost minimization analysis of beta-blocker at the time of CT imaging for suspected of coronary heart disease in Japan. J Med Econ. 2014;17(2):142-147.
Research Reports in Clinical Cardiology

\section{Publish your work in this journal}

Research Reports in Clinical Cardiology is an international, peerreviewed, open access journal publishing original research, reports, editorials, reviews and commentaries on all areas of cardiology in the clinic and laboratory. The manuscript management system is completely online and includes a very quick and fair peer-review system.

\section{Dovepress}

Visit http://www.dovepress.com/testimonials.php to read real quotes from published authors. 